\title{
EIDE
}

Foundations of Ontology

Series Editors

Otávio Bueno, Javier Cumpa, John Heil, Peter Simons, Erwin Tegtmeier, Amie L. Thomasson

\section{Volume 9}


Francesco F. Calemi (Ed.)

Metaphysics and

Scientific Realism

Essays in Honour of David Malet Armstrong

Edited by

Francesco F. Calemi 
Copyright-Text

ISBN 978-3-11-045461-1

e-ISBN (PDF) 978-3-11-045591-5

Library of Congress Cataloging-in-Publication Data

A CIP catalog record for this book has been applied for at the Library of Congress.

Bibliographic information published by the Deutsche Nationalbibliothek

The Deutsche Nationalbibliothek lists this publication in the Deutsche Nationalbibliografie; detailed bibliographic data are available on the Internet at http://dnb.dnb.de.

(c) 2015 Walter de Gruyter GmbH, Berlin/Munich/Boston

Cover image: Cover-Firma

Typesetting: le-tex publishing services $\mathrm{GmbH}$, Leipzig

Printing and binding: Druckerei XYZ

(2) Printed on acid-free paper

Printed in Germany

www.degruyter.com 


\section{Tuomas E. Tahko}

\section{Armstrong on Truthmaking and Realism}

\section{Introduction}

The title of this paper reflects the fact truthmaking is quite frequently considered to be expressive of realism. What this means, exactly, will become clearer in the course of our discussion, but since we are interested in Armstrong's work on truthmaking in particular, it is natural to start from a brief discussion of how truthmaking and realism appear to be associated in his work. Armstrong's interest in truthmaking and the integration of the truthmaker principle to his overall system happened only later in his career, especially in his 1997 book A World of States of Affairs and of course the 2004 Truth and Truthmakers. Since the 2004 book is the most complete account of Armstrong's thinking with regard to truthmaking, that book will be our primary source (especially given that he changed his mind about a few issues between the 1997 and the 2004 books). The theme is certainly present in his earlier work as well, but the notion of truthmaking, which Armstrong got from C. B. Martin, was not as well formulated in the literature. The seminal paper by Mulligan, Simons and Smith (1984) had not yet popularised the notion. In the introduction to his Truth and Truthmakers, Armstrong outlines the origins of the notion in Australia: Martin used the idea of truthmaking in his work against counterfactual accounts of material objects due to the phenomenalists. Armstrong himself first took advantage of the truthmaker principle in his attempt to resist dispositional/subjunctive accounts of mental states due to behaviourists such as Gilbert Ryle (Armstrong 1973, 11ff.). The now famous slogan, according to which the truthmaker insight 'prevents the metaphysician from letting dispositions "hang on air"' originates in Armstrong's criticism of Ryle (Armstrong 2004, 3).

It is thus partly because of this historical usage of the 'truthmaker insight' that truthmaking is often associated with realism. But the situation is certainly more complicated than that when we look into the details. One reason for the complications regarding truthmaking and its potential ability to capture realist intuitions is that many of the best known theories of truthmaking are very closely tied to certain ontological views that already make realist commitments. Among these is Armstrong's own version of truthmaking, which is integrated with his ontology of states of affairs. Naturally, the states of affairs ontology has some important implications for his conception of truthmaking. The most obvious of these implications

Tuomas E. Tahko: University of Helsinki, email: tuomas.tahko@helsinki.fi 
is that, according to Armstrong, truthmakers are facts - albeit he prefers to call them states of affairs: 'entities having such forms as a's being $\mathrm{F}$ and a's having $\mathrm{R}$ to b' (Armstrong 2004, 18). Of course, as Armstrong $(2004,4)$ readily admits, the idea of truthmaking can be separated from the question of what truthmakers in fact are. In any case, for Armstrong the truthbearers are true propositions - although there are some caveats, e.g., he considers propositions to be 'possible intentional objects' and takes it that a 'naturalist' cannot accept a realm of propositions (ibid., 16; 1997, 131).

Moving on to the truthmaking relation, there are a couple of things that, I believe, can be said without much controversy. One of these is that whatever we take the actual truthmakers to be, and, I suppose, even regardless of the nature of the supposed truthmaking relation between propositions and reality, we can in any case say that the (possible) correspondence between a proposition and the reality, i.e., between the proposition and the truthmaker, is not, in general, a one-one correspondence. ${ }^{1}$ This is the view that Armstrong $(2004,16)$ takes and, in essence, seems to be what many other proponents of truthmaking would go for as well (see for example Lowe 2006, 182). The reason for opting for a many-many relation is simple enough: a single truthmaker can quite clearly be a truthmaker for several truthbearers and correspondingly there might be several truthmakers which serve as a sufficient truthmaker for a given proposition. Perhaps it could be argued that there is always some minimal truthmaker for each truth, but as Armstrong points out, many truths do also have several minimal truthmakers, such as the proposition <there exists an $\mathrm{x}$ such that $\mathrm{x}$ is a human being> (Armstrong 2004, 21). ${ }^{2}$ Another aspect that appears to be fairly uncontroversial is that truthmaking is some kind of an asymmetrical relation between propositions and something in the world. This something in the world could be facts or states of affairs, as in Armstrong's case, or tropes, or something quite different, depending on your account of truthmakers. Another way to put this is to say that a truthmaker for a particular truth is some portion of reality in virtue of which the truth is true. This 'in virtue of' relation is generally thought to be cross-categorical, the portion of reality being some entity or entities and the other being truth (which is not an entity!) (see Armstrong 2004, 5).

The exact nature of the truthmaking relation is not uncontroversial though: one possibility is that it is an entailment relation between the truthmaker and the truth of the proposition, but it has also been argued that we are dealing with a

1 Note that 'propositions' could be considered merely as a placeholder here, depending on one's take on what the truthbearers are.

2 Where the angled brackets describe a proposition, following Horwich 1998. For discussion on minimal truthmakers, see Tahko and O'Conaill forthcoming. 
grounding relation here, in which case truth would be grounded in entities (cf. Rodriguez-Pereyra 2005). There is also the question of whether truthmaking is an internal or an external relation (Armstrong 1997, 115-116). Armstrong favours the first alternative, and it does perhaps seem initially more plausible that truthmaking is an internal relation, but there are various problems with this idea as well (cf. David 2005). Each of these issues would require a paper of its own, but we will mostly set them aside here, focusing instead on the more general question regarding truthmaking and realism. However, we will need at least an initial formulation of the truthmaking relation to get started. Take one formulated in terms of the 'in virtue of' locution, which produces a familiar truthmaker principle:

(TM) Necessarily, if a proposition $\langle p\rangle$ is true and has a truthmaker, then there is some entity in virtue of which it is true.

This formulation of (TM) entails (though is not the same as) Truthmaker Necessitarianism: the existence of a truthmaker is sufficient for the truth of those propositions it makes true. Armstrong (2004, 5-7) defends Truthmaker Necessitarianism, appealing to the slogan mentioned above, i.e., if a given truth (a true proposition) would lack a truthmaker, then its truth would 'hang on air' quite like Ryle's dispositional truths. Indeed Truthmaker Necessitarianism is a widely shared assumption amongst truthmaker theorists, even though it is difficult to come up with a conclusive argument in favour of it:

I do not have any direct argument [for Truthmaker Necessitarianism]. My hope is that philosophers of realist inclinations will be immediately attracted to the idea that a truth, any truth, should depend for its truth for something 'outside' it, in virtue of which it is true. (Armstrong 2004, 7.)

We will not discuss Truthmaker Necessitarianism in much more detail than this, nor the other one of Armstrong's controversial theses, Truthmaker Maximalism, i.e., the thesis that every truth must have a truthmaker. ${ }^{3}$ (TM) does not, of course, entail Truthmaker Maximalism.

\section{Truthmaking and realism}

It is well-known that Armstrong postulates an intimate connection between truthmaking and realism. The mediator here is correspondence, or more precisely, the

3 For a brief defence of Truthmaker Maximalism, see Rodriguez-Pereyra 2006. 
correspondence theory of truth. It appears that, for Armstrong, truthmaker theory could be understood simply as a more sophisticated version of the correspondence theory. There are several passages in Armstrong's work that explicitly suggest this:

[T]he Correspondence theory tells us that, since truths require a truthmaker, there is something in the world that corresponds to a true proposition. The correspondent and the truthmaker are the same thing. $(1997,128)$

Propositions correspond or fail to correspond to reality. [If Armstrong's view of propositions is correct], then it becomes pretty clear that the correspondence theory of truth can and should be upheld. $(2004,16)$

The terms of the correspondence relation are truthmakers and truths. Truthmakers entail truths. Our favoured truthmakers are states of affairs or their constituents. $(1997,131)$

Note however that especially in A World of States of Affairs, Armstrong emphasises that truthmaker theory is not only compatible with (the idea of) the correspondence theory of truth, but also with the redundancy theory of truth (if it is to be called a theory of truth at all) $(1997,128) .{ }^{4}$ Be that as it may, in the secondary literature Armstrong's appeal to the correspondence theory in his formulation of the truthmaker theory has been received with some hostility. Typically, this is because the motivation seems to be exactly to argue in favour of realism. Consider how Helen Beebee and Julian Dodd put it in their influential volume on truthmaking:

Suppose that some formulation of truthmaker theory does indeed succeed in capturing realist intuitions. The question arises, how can truthmaker theory now legitimately be put to use in an argument for realism (about a particular domain) and against anti-realism? If truthmaker theory itself enshrines a commitment to realism, then presumably the appropriate anti-realist reaction to such an argument is simply to deny whatever truthmaker principle is being used as a premise in that argument. If a given truthmaker principle is to pull its weight in arguments against anti-realism, then we had better have reasons, independently of our commitment to realism, for believing that the principle is true. We wonder whether such reasons are to be had. (Beebee and Dodd 2005, 16.)

\footnotetext{
4 Incidentally, one might also ask whether the truthmaker theory is a theory of truth. Certainly, if we have merely a stripped down truthmaker principle, then we are not dealing with a complete theory of truth. But once the truthmaker principle is combined with an appropriate ontology, then I would be inclined to say that we do indeed have a complete theory of truth, as we can give a full account of the truthbearers and the truthmakers. But the core of truthmaking is the truthmaker principle, and if it turns out to be compatible with different ontologies (as will be proposed below), then it is at least a promising starting point for a complete theory of truth.
} 
So if Armstrong's postulated connection between truthmaker theory and realism truly holds, then Beebee and Dodd insist that we should be able to put forward a truthmaker principle that would be able to capture our realist intuitions while not being compatible with anti-realism. Even if we were to succeed, we would still have to show that there are reasons, independently of our realist intuitions, to believe that our truthmaker principle is the correct one, as otherwise the use of truthmaking in arguments against anti-realism will just be question-begging. Perhaps this can be done, but as we have seen, Armstrong's own project seems to postulate a very intimate connection between truthmaking and realism.

However, if we were to concede that truthmaker theory fails to cash out our realist intuitions, at least without leaving room for other interpretations, then what would the cost be, precisely? Well, provided that truthmaker theory is at least compatible with realism - which it surely is - then the possibility that it might be able to accommodate other than realist intuitions might not be so harmful. In other words, if truthmaking turned out to be an ontologically neutral way of talking about truth we could of course still combine it with a realist ontology. Now, this is of course not an answer to the challenge posed by Beebee and Dodd. Rather, the proposal is that the price that Armstrong might have to pay is not all that high. But this line of argument is only feasible once it is clear that truthmaker theory can be presented in an ontologically neutral way and if realism itself can stand on its own. So let us now move to a discussion of truthmaker theory combined with various alternatives to realism.

\section{Truthmaking as ontologically neutral}

If we wish to find an ontologically neutral formulation of the truthmaker principle, then this is likely to impose some constraints on the theory. For that reason, certain usual formulations are unlikely to work. Consider one typical formulation, as presented by Beebee and Dodd:

(TM-E) Necessarily, if $\langle p\rangle$ is true, then there exists at least one entity $\alpha$ such that $<\alpha$ exists $>$ entails $\langle<p>$ is true $>$. (Beebee and Dodd 2005, 2.)

The nature of the truthmaking relation, here suggested to be an entailment relation, is perhaps the most controversial part of (TM-E). Of course, other problems may emerge when certain truths, such as necessary truths or negative truths are considered. There have been numerous attempts to deal with these problems, but the details of each solution depend, often heavily, on the details of the ontology that one wishes to combine with truthmaking, and accordingly these problems 
are not something that we should focus on here. However, a somewhat neutral way to address the problems involved with entailment is to replace entailment with (metaphysical) necessitation: in every possible world where a truthmaker for a certain proposition exists, that proposition is true. This is the line that was taken in the initial formulation given in this paper (TM) and it would seem to be preferable to Armstrong $(1997,115)$ as well (see also Lowe 2006, 185).

Some key features of the truthmaker principle were listed earlier and at least some of them would also seem to hold in regard to the general principle that we are now looking for. So, we can for example without much risk of controversy say that truthmaking is an asymmetrical many-many relation. Also, as Rodriguez-Pereyra (2005, 20-1) suggests, we seem to have the intuition that truth is asymmetrical, and the truthmaker principle fits this intuition perfectly. The way that RodriguezPereyra puts it is that truth is grounded: the truth of a proposition depends on what reality is like, and the relationship between truth and reality is of course asymmetrical, for reality does not depend on the truth of the proposition. As he points out, this by itself does not commit us to realism, for an idealist (for instance) could just add that reality or world and the entities in it are not mind-independent (ibid.).

Moreover, Chris Daly (2005) has suggested that there is one issue that advocates of different truthmaker theories always agree upon: truthmaking does some explanatory work. This is of course a rather natural source for motivation to adopt truthmaker theory in the first place. Ultimately, this motivation concerns the nature of the truthmaking relation, for whatever explanatory work the truthmaker principle might do, it must surely have something to do with the relationship between propositions and truthmakers. So what are our options for motivating truthmaking? According to Daly $(2005,102)$, there are three options. The first one is what he calls the 'Canadian mountie' theory of truthmakers, the idea of which is to argue from examples and to show that we can, in fact, always find a truthmaker for any given truth. Daly accuses this theory of being $a d h o c$, in that it assumes the truthmaker principle without giving any justification for it. Presumably the point is that we need more than a working theory of truthmaking to motivate the idea in the first place. This would appear to be a valid request.

The second strategy suggests that truthmaker theory could help in finding explanations to further ontological problems, such as the theory of universals. Daly (2005, 98-102) argues against Rodriguez-Pereyra's suggestion, namely that truthmakers could explain universals by entailing that it is true that there are some properties which are shared by several distinct particulars. There are other alternatives as well though, one of them being Josh Parsons's (2005) rather plausible idea that truthmaking could be used to motivate arguments concerning propositions about the past and the future and thus might provide some explanatory 
power when discussing theories of time, such as presentism. However, while I am not against the idea of granting the possibility that truthmaking could help motivate arguments concerning other ontological problems, I do not believe that this by itself is a sufficient condition for adopting the truthmaker principle; and neither, of course, does Daly.

The third strategy that Daly $(2005,94-8)$ considers, namely inference to the best explanation, is perhaps the most common. According to this strategy, truthmaking explains our pro-realism intuitions and grasps the core idea of the correspondence theory of truth. This is of course the core motivation that we are now interested in. Daly considers Armstrong's and Bigelow's theories in this connection. Here we are faced with the central question: could truthmaking offer a way to characterise a theory of truth compatible with realism? But we have to be careful here, for even if truthmaking is compatible with realism, it does not mean that it would explain why realism is any better than other alternatives. Indeed, it seems that the truthmaker principle is in no way connected with any necessarily realist premises, especially if it is compatible with, say, pragmatism and idealism as well (which is a suggestion we will consider briefly below).

There is one further complication. Recall that Armstrong seems to consider truthmaking to be effectively a more sophisticated version of the correspondence theory - and this is in fact a major reason for the claim that it captures realist intuitions. If this were indeed the case, then it would seem difficult to combine truthmaking with anything but realism. But this is where things get interesting, for Daly argues that the same ontological neutrality thesis applies to the Correspondence Intuition $(\mathrm{CI})$ as well, formulated in the following way:

(CI) $<p>$ is true if and only if things are as $<p>$ says they are. (Daly 2005: 96.)

The apparent problem with (CI), however, is that it appears to be vacuous: (CI) is compatible with just about any theory of truth, and hence its explanatory value cannot be particularly high. So, if truthmaker theory is supposed to be explanatory, it better capture something more than just (CI). Armstrong himself (2004: Ch. 4) certainly claims that the truthmaker principle could say something more than (CI) does - this will be done by combining the correspondence relation with the truthmaker principle and his states of affairs ontology - but consider Daly's analysis of (CI):

Consider the coherence theorist. He may consistently say 'If $\langle p\rangle$ is true, it has a truthmaker. $\langle p\rangle$ corresponds to a state of affairs, namely the state of affairs which consists of a relation of coherence holding between $\langle p>$ and the other members of a maximal set of propositions'. Consider the pragmatist. He may consistently say, 'If $\langle p\rangle$ is true, it has a truthmaker. $\langle p\rangle$ corresponds to a state of affairs, namely the state of affairs of $\langle p\rangle$ 's having the property of 
being useful to believe'. It is controversial whether there exist states of affairs. Let that pass. My point here is that the coherence theory and the pragmatic theory are each compatible with the admission of states of affairs. Furthermore, each of these theories is compatible with the admission of states of affairs standing in a correspondence relation to truths. (Daly 2005, 97)

So Daly's case against the third strategy (to guarantee the explanatory value of truthmaker theory and hence motivate it) is based on the claim that the truthmaker principle does not restrict our choices in terms of ontology in any way and thus truthmaking understood in the lines of Armstrong and Bigelow is just as vacuous as (CI). This is indeed a valid concern, for if truthmaking is understood as a special case of the correspondence theory, then it seems to inherit all of its original problems.

However, it seems trivial that the truthmaker principle could be combined with different ontologies once we acknowledge the idea that truthmaking is quite separate from the varying answers concerning the actual truthmakers and truthbearers. Furthermore, as already noted, Armstrong (2004: 4) seems to have no quarrel with the idea that truthmaking may be compatible with very different accounts of truthmakers and truthbearers. This is really the only thing that counts: it ought to be one's account of truthmakers and truthbearers that introduces the (important) ontological commitments, not the truthmaker principle itself. Accordingly, I think that Armstrong and other advocates of realist truthmaker theories could very well be content with a somewhat weakened condition when it comes to the truthmaker principle, namely, that the truthmaker principle is the best way to characterise the correspondence relation understood in a realist sense. When put like this, the details of our ontology are still open, but the motivation for truthmaking is still clear: it is the best way to formulate the realist understanding of the correspondence relation. This hints towards a fourth strategy for motivating truthmaking in addition to the three suggested by Daly, and in fact I think that the fourth strategy is closer to how most truthmaker theorists would like to motivate their theories.

\section{Realism can stand on its own}

The strategy for motivating truthmaking that is now emerging rests on this very simple point: realism can stand on its own. In other words, we do not need truthmaking (or the correspondence theory, for that matter) to motivate realism. This reflects Michael Devitt's (1997) classic work on the topic of realism and truth. Compared to Daly's third strategy, this changes the direction of explanation. It could 
be said that the fourth strategy does not so much try to provide an explanation, but a justification, although in another sense it can be thought to provide an explanation as well, as we will shortly see. In any case, what is important is that because realism can stand on its own, those of us who are realists can motivate truthmaking with realism - not the other way around. While this type of strategy is not clearly present in Armstrong's writings, I do believe that he might have welcomed it.

If we start with a realist ontology and if truthmaking increases the plausibility of the overall theory, then it seems rather straightforward to choose the way to go: realism plus truthmaking is the best theory available. But in order for this strategy to be plausible, we ought to see some more evidence to the effect that, say, idealists or pragmatists would also be happy with the proposed truthmaker principle. To this effect, the principle would have to be such that an idealist or pragmatist could insert their desired truthmakers and truthbearers into the principle. There may be some limitations here. For one thing, on all the usual formulations, the truthmakers are taken to be entities of some kind. It is certainly a matter of debate what kind of entities they are, but it might be objected that, say, a pragmatist would not be happy about the commitment to 'entities' in any form whatsoever. So how could pragmatism be compatible with truthmaking? Positive accounts arguing to this effect are scarce, but Sami Pihlström (2005) has outlined some options. Pihlström suggests that pragmatists such as Hilary Putnam (at times) and Nelson Goodman could very well be considered as taking advantage of a version of truthmaking, whereby the truthbearers and the 'world' that makes them true (i.e., the truthmakers) are human constructions, 'made' by us in the process of representing and acting. Now, whether this constitutes a commitment to entities or not is perhaps debatable - maybe 'human constructions' are to be considered as entities. But there appears to be no reason why this type of picture couldn't be represented with a truthmaker principle not unlike the ones we have been discussing.

A more general point to note is the following. If we take truthmakers to be entities, there are several alternatives available, such as Armstrong's states of affairs or tropes, as suggested in Mulligan, Simons and Smith (1984). There is not much that can be said about the nature of the truthmakers without a commitment to a particular ontology. However, personally I would be inclined to part ways with Armstrong here, for it seems to me that the apparent complexity of truth suggests that truthmakers must be spread out in several different categories rather than just one. This complexity manifests itself in the variety of things we consider to be true: mathematical theorems, laws of physics, that Hesperus and Phosphorus are identical, and so on. Introducing a further category of facts or states of affairs to account for all truthmakers is not ontologically parsimonious; why not say that 
the truthmakers are just the very entities that a given true proposition concerns? This line of thought has also been noted by Beebee and Dodd $(2005,9)$ and it is exactly what Lowe (2005, 182 ff.) argues for as well.

Returning to the issue concerning a commitment to entities, we might note that one could attempt to formulate truthmaking in a manner that does not entail a commitment to entities at all, perhaps in the lines of McFetridge's (1990) suggestion that every true sentence must have an explanation of why it is true. This would seem to release us from the commitment to entities, but it also distances us from the original idea of truthmaking. In fact, it appears that this would take us back towards a vacuous principle. McFetridge's proposal is another attempt to combine truthmaking and our realist intuitions so that we would have an argument against anti-realism (see Liggins 2005 for details of how this might be done). This is a line of thought that we have already distanced ourselves from. Of course, we can easily modify the truthmaker principle in such a way that an explicit commitment to entities is removed, but it is questionable whether this really does the trick. Consider $\left(\mathrm{TM}^{\star}\right)$ :

$\left(\mathrm{TM}^{\star}\right)$ Necessarily, if a proposition $\langle p>$ is true and has a truthmaker, then there is some $\alpha$ in virtue of which it is true.

Here the entailment relation has been replaced with metaphysical necessitation, as in the original (TM). In fact, you'll notice that $\left(\mathrm{TM}^{\star}\right)$ differs from the original (TM) only in replacing the explicit reference to entities with a reference to the unspecified ' $\alpha$ '. Have we been moving in circles? Not as such: what has changed is the order of explanation. Truthmaking is now understood as a tool to help characterise one's ontology, not a way to motivate the ontology itself. To that effect, all we need is that the truthmaker principle is compatible across different ontologies. $\left(\mathrm{TM}^{\star}\right)$ is obviously compatible with realist ontologies, in which case it is likely that we would want to add that what makes $\langle p>$ true is the existence of an entity of some kind. A pragmatist, on the other hand, could replace $\alpha$ with 'human construction', as suggested by Pihlström. Whether or not this avoids the commitment to entities is another question, but one that I consider an ancillary issue. As for idealists, they could presumably interpret existence so that it does not require material existence, although I am not aware of any idealist accounts which would employ truthmaking explicitly.

Naturally, we need to add something to $\left(\mathrm{TM}^{\star}\right)$ to give it any explanatory power, as the nature of the truthmaking relation depends on what $\alpha$ is - and now also on how we interpret existence. Indeed, ( $\left.\mathrm{TM}^{\star}\right)$ is just the spine of truthmaking as we need to say something about $\alpha$ to determine how it makes $<\mathrm{p}>$ true. However, the relative weakness of $\left(\mathrm{TM}^{\star}\right)$ is exactly why the principle is plausible across ontolo- 
gies: it could perhaps be interpreted as a family of relations that covers all possible kinds of truthmakers. Of course, in $\left(\mathrm{TM}^{\star}\right)$ the truthbearers are still taken to be propositions, which might not satisfy everyone (or every ontology). But I would not be too concerned about this, given that Armstrong himself wishes to avoid a commitment to propositions and reinterprets them as 'possible intentional objects', in accordance with his naturalistic agenda. Accordingly, perhaps there is room to interpret propositions as well in accordance with various ontologies.

The upshot is that truthmaking is not, or does not have to be, an explanation for, or a case in favour of our realist intuitions. Perhaps truthmaking does increase the appeal of realism, for the explanatory power of the complete theory (realism plus truthmaking) is certainly greater with truthmaking than without it. In this sense, truthmaking may still make a contribution towards explanatory power. But an idealist or a pragmatist could attempt to make the same claim. In any case, there are strong reasons to think that the question of realism is independent of the question of truth. Armstrong may have wanted something more than this out of truthmaker theory, nevertheless, truthmaker theory is a plausible way to account for truth within a realist ontology. A particularly forceful reason to think so is that, in the lines of Michael Dummett's (e.g. 1991) influential work, the anti-realist's strongest case against realism may be exactly that realism is unable to account for truth in a satisfactory manner, given the shortcomings of the correspondence theory. If truthmaker theory can now offer an ontologically neutral way to account for truth, then this argument dissipates. Realism can stand on its own, and truthmaking is a way to account for truth regardless of one's ontology. This is really all that Armstrong or any realist proponent of truthmaker theory needs: a way to account for truth within a realist ontology.

\section{Bibliography}

Armstrong, D. M. 1973. Belief, Truth and Knowledge. Cambridge: Cambridge University Press. Armstrong, D. M. 1997. A World of States of Affairs. Cambridge: Cambridge University Press. Armstrong, D. M. 2004. Truth and Truthmaking. Cambridge: Cambridge University Press. Beebee, H. and Dodd, J. (eds.) 2005. Truthmakers: The Contemporary Debate. Oxford: Oxford University Press.

Daly, C. 2005. “So Where's the Explanation?” In Beebee, H. and Dodd, J. (eds.) 2005, 85-103. David, M. 2005. “Armstrong on Truthmaking”. In Beebee, H. and Dodd, J. (eds.) 2005, 141-59. Devitt, M. 1997. Realism and Truth, 2nd edn. Princeton: Princeton University Press. Dummett, M. 1991. The Logical Basis of Metaphysics. Cambridge, MA: Harvard University Press.

Horwich, P. 1998. Truth, 2nd edn. Oxford: Oxford University Press. 
Liggins, D. 2005. “Truthmakers and Explanation”. In Beebee, H. and Dodd, J. (eds.) 2005, 10515.

Lowe, E. J. 2006. The Four-Category Ontology: A Metaphysical Foundation for Natural Science. Oxford: Oxford University Press.

McFetridge, I. 1990. “Truth, Correspondence, Explanation and Knowledge”. In his Logical Necessity and Other Essays. London: Aristotelian Society.

Mulligan, K., Simons, P. and Smith, B. 1984. “Truth-Makers”. Philosophy and Phenomenological Research 44: 287-321.

Parsons, J. 2005. “Truthmakers, the Past, and Future.” In Beebee, H. and Dodd, J., 161-74.

Pihlström, S. 2005. "Truthmaking and Pragmatist Conceptions of Truth and Reality”. Minerva An Internet Journal of Philosophy 9. URL $=<$ http://www.ul.ie/ philos/vol9/Truthmaking. html>.

Rodriguez-Pereyra, G. 2005. "Why Truthmakers". In Beebee, H. and Dodd, J. (eds.), 17-31.

Rodriguez-Pereyra, G. 2006. “Truthmaker Maximalism Defended”. Analysis 66 (3): 260-64.

Tahko, T. E. and O'Conaill, D. forthcoming. "Minimal Truthmakers”. Pacific Philosophical Quarterly. 